\title{
Effects of intraoperative breaks on mental and somatic operator fatigue: a randomized clinical trial (Surg Endosc 2011;25:12; 1245-1250)
}

\author{
Carsten Engelmann • Benno Ure
}

Received: 22 March 2012/Accepted: 16 April 2012/Published online: 31 May 2012

(C) Springer Science+Business Media, LLC 2012

With great interest we read the letter of Rieger et al. on work-related stress. In contrast to the authors, we did not investigate the effects of lead gowns.

The results reported in the letter illustrate Wickens' classical multi resource theory published in 1991 [1]. It states that one given task produces demand on various personal resources, including psychological and physical resources. This is confirmed by the authors of the letter.

However, stress is a normal phenomenon and to some extent desirable. It remains of particular interest whether a stress reduction programme achieves greater concentration of surgeons, and secondly, which kind of operations are most suitable for such programmes. Finally, it remains to be investigated how stress reduction measures should be shaped and how their acceptance by surgeons can be achieved.

\section{References}

1. Wickens CD (1991) Processing resources and attention. In: Damos DL (ed) Multiple-task performance. Taylor \& Francis, London, pp 3-34
C. Engelmann $(\bowtie) \cdot$ B. Ure

Department of Pediatric Surgery, Hannover Medical School,

Carl Neuberg St. 1, 30625 Hannover, Germany

e-mail: ceng@bdc.de

B. Ure

e-mail: ure.benno@mh-hannover.de 